\title{
New endoscopic images of mucosal prolapse syndrome
}

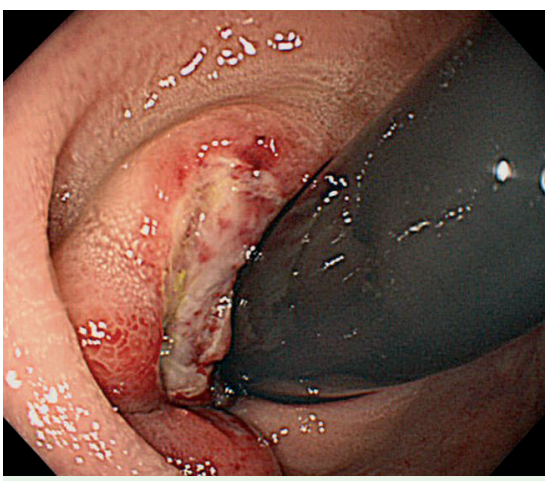

Fig. 1 Colonoscopy showing a polypoid lesion with central ulceration in the lower rectum of a patient with bleeding per rectum and fecal incontinence.

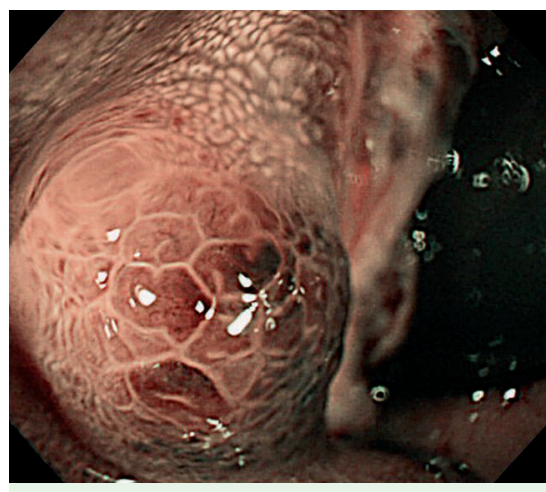

Fig. 2 Dilated, brownish pits and widened pericryptal space in the region of the lesion visualized on magnifying colonoscopy.

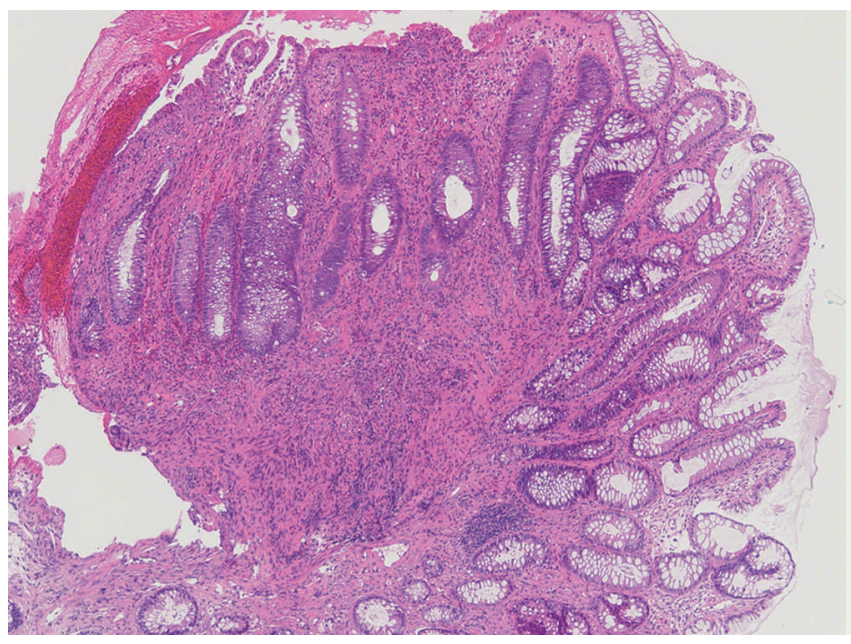

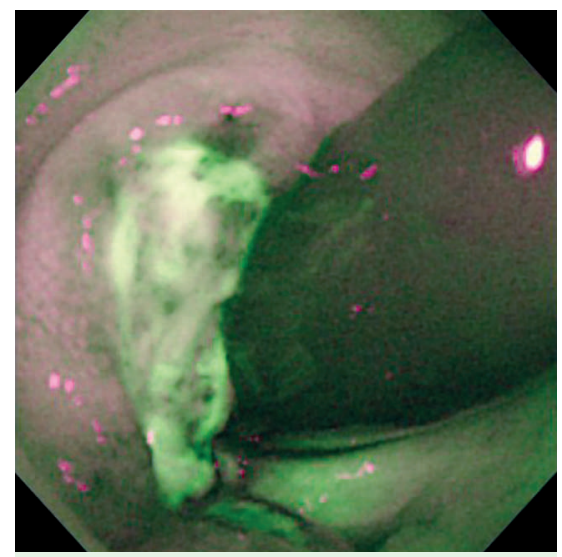

Fig. 3 Autofluorescence imaging (AFI) findings: a magenta-colored elevation surrounds the yellowish-green ulcerated area.

Fig. 4 Microscopic examination shows elongation and distortion of the crypts and fibromuscular obliteration in the mucosa.

\section{Bibliography}

DOI $10.1055 / \mathrm{s}-0029-1214624$

Endoscopy 2009; 41: E136

(c) Georg Thieme Verlag KG Stuttgart · New York . ISSN 0013-726X

\section{Corresponding author}

\section{C. Chen, MD, H. Isomoto, MD}

Second Department of Internal Medicine Nagasaki University School of Medicine

1-7-1 Sakamoto

Nagasaki 852-8501

Japan

Fax: +81-95-8497285

cszen@hotmail.com

hajimei2002@yahoo.co.jp
A 65-year-old man presented with hematochezia and fecal incontinence. For a long time he had been experiencing severe constipation and had needed to train to evacuate the bowels. Conventional colonoscopy revealed a hyperemic broad-based polypoid lesion with central ulceration in the lower rectum ( $\bullet$ Fig. 1). Magnifying colonoscopy with narrowband image system (NBI) revealed dilated brownish, oval-to-long pits and widening of the pericryptal space around the polypoid lesion ( $\bullet$ Fig. 2). There was no destruction of or irregularity in the pit pattern and no abnormalities in the microvessels. Autofluorescence imaging (AFI) revealed a magenta-colored elevation surrounding the yellowish-green ulcerated area ( Fig. 3). Histological examination of biopsy specimens taken from the polypoid lesion revealed elongation and distortion of the crypts and fibromuscular obliteration in the mucosa ( Fig. 4). On the basis of the clinicopathological features, a diagnosis of mucosal prolapse syndrome was made. The patient was successfully treated with bowel retraining to avoid straining at defecation and dependence on laxatives.

\section{Endoscopy_UCTN_Code_CCL_1AD_2AJ}

\section{C. Chen ${ }^{1}$, H. Isomoto ${ }^{1}$, H. Ishii ${ }^{1}$,}

T. Hayashi' ${ }^{2}$, Y. Mizuta ${ }^{1}$, S. Kohno ${ }^{1}$

1 Second Department of Internal

Medicine, Nagasaki University School of Medicine, Nagasaki, Japan

2 Department of Pathology, Nagasaki

University School of Medicine, Nagasaki, Japan 